\title{
Research Paper A generalized class of synthetic estimator with application to estimation of milk production for small domains
}

\section{Archana, S.E.H. Rizvi, Manish Kr. Sharma and M. Iqbal Jeelani Bhat}

ABSTRACT : The demand for small area statistics is growing day-by-day not only in public but also in private sectors, and small area estimation technique (SAE) is becoming very important in survey sampling due to the thrust of planning process has shifted from macro to micro level. Small area estimation is one of the several techniques which involves the estimation of parameters for small subpopulation generally used when the sub-population of interest is included in a larger survey. In this article the proposed class of synthetic estimators gives consistent estimators if the synthetic assumption holds. Further it demonstrates the use of the generalized synthetic and ratio synthetic estimators for estimating the milk production for small domains, empirically through a real data set.

KEY WORDS : Synthetic estimator, Small area estimation, Small area

How To Cite This PAper : Archana, Rizvi, S.E.H., Sharma, Manish Kr. and Bhat, M. Iqbal Jeelani (2019). A generalized class of synthetic estimator with application to estimation of milk production for small domains. Internat. Res. J. Agric. Eco. \& Stat., 10 (1) : 115-121, DOI : 10.15740/HAS/IRJAES/10.1/115-121. Copyright@ 2019: Hind Agri-Horticultural Society. 